\title{
RESEARCH
}

Open Access

\section{The global end-ranges of neck flexion and extension do not represent the maximum rotational ranges of the cervical intervertebral joints in healthy adults - an observational study}

\author{
Victoria Andersen ${ }^{1 *}$ (D, Xu Wang ${ }^{2 *}$, Mark de Zee ${ }^{3}$, Lasse Riis Østergaard', Maciej Plocharski ${ }^{1}$ and René Lindstroem ${ }^{1}$
}

\begin{abstract}
Background: In clinical diagnosis, the maximum motion of a cervical joint is thought to be found at the joint's end-range and it is this perception that forms the basis for the interpretation of flexion/extension imaging studies. There have however, been representative cases of joints producing their maximum motion before end-range, but this phenomenon is yet to be quantified.

Purpose: To provide a quantitative assessment of the difference between maximum joint motion and joint endrange in healthy subjects. Secondarily to classify joints into type based on their motion and to assess the proportions of these joint types.
\end{abstract}

Study design: This is an observational study.

Subject sample: Thirty-three healthy subjects participated in the study.

Outcome measures: Maximum motion, end-range motion and surplus motion (the difference between maximum motion and end-range) in degrees were extracted from each cervical joint.

Methods: Thirty-three subjects performed one flexion and one extension motion excursion under video fluoroscopy. The motion excursions were divided into 10\% epochs, from which maximum motion, end-range and surplus motion were extracted. Surplus motion was then assessed in quartiles and joints were classified into type according to end-range.

Results: For flexion $48.9 \%$ and for extension $47.2 \%$ of joints produced maximum motion before joint end-range (type S). For flexion $45.9 \%$ and for extension $46.8 \%$ of joints produced maximum motion at joint end-range (type C). For flexion $5.2 \%$ of joints and for extension $6.1 \%$ of joints concluded their motion anti-directionally (type A). Significant differences were found for $C 2 / C 3(P=0.000), C 3 / C 4(P=0.001)$ and $C 4 / C 5(P=0.005)$ in flexion and $C 1 /$

\footnotetext{
* Correspondence: veba@hst.aau.dk; x.wang2013@hotmail.com

'Department of Health Science and Technology, Aalborg University, 9220 Aalborg, Denmark

${ }^{2}$ The Second Hospital of Jilin University, Jilin University, Qianjin St. 2699, Changchun 130021, China

Full list of author information is available at the end of the article
}

C C The Author(s). 2021 Open Access This article is licensed under a Creative Commons Attribution 4.0 International License, which permits use, sharing, adaptation, distribution and reproduction in any medium or format, as long as you give appropriate credit to the original author(s) and the source, provide a link to the Creative Commons licence, and indicate if changes were made. The images or other third party material in this article are included in the article's Creative Commons licence, unless indicated otherwise in a credit line to the material. If material is not included in the article's Creative Commons licence and your intended use is not permitted by statutory regulation or exceeds the permitted use, you will need to obtain permission directly from the copyright holder. To view a copy of this licence, visit http://creativecommons.org/licenses/by/4.0/. The Creative Commons Public Domain Dedication waiver (http://creativecommons.org/publicdomain/zero/1.0/) applies to the data made available in this article, unless otherwise stated in a credit line to the data. 


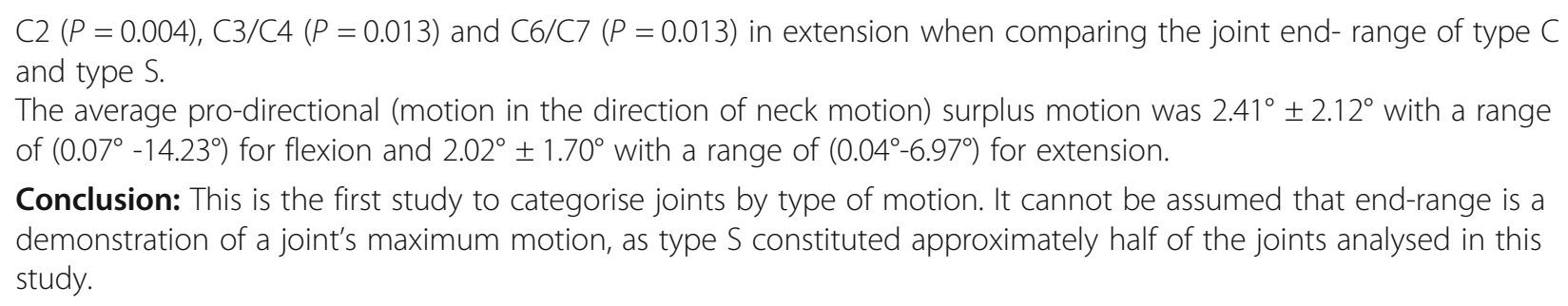

Keywords: Maximum motion, Range of motion, Fluoroscopy, Cervical vertebrae, Neck

\section{Introduction}

Neck range of motion (ROM) is a traditional method employed for the assessment of neck motion in both clinical and scientific environments [1-5]. Neck ROM is frequently assessed as a change of head position from the forward-facing upright head position to a new position after movement of the neck. Neck ROM is assessed between the head and a lower anatomical point, commonly the chin and sternal notch [6]. Neck ROM can further be divided into the motions of joints between two cervical vertebrae. Although there are multiple intervertebral joints between two cervical vertebrae (intervertebral, facet and uncovertebral joints), the multi-joint complex will henceforward be referred to as a joint.

The largest cervical joint motion associated with neck ROM in clinical diagnosis is perceived to be found at the end of the (global) neck movement [7, 8]. This perception is used in the interpretation of flexion and extension $\mathrm{X}$-rays to measure the maximum joint motion. However, neck ROM contains little information about motion between the measuring points, as the measurements are taken from static positions. Studies have demonstrated representative cases where the maximum joint motion is greater than the motion found at the joint's end-range [9-11]. Thus, in these cases the joint position at end-range could not represent the maximum joint motion.

New studies document multiple sources of joint motion variability, demonstrating that cervical joint motion cannot be perceived to be curvilinear or uniform [9-12]. Cervical joints have been demonstrated to repeat their motion and investigations of within and between day repartitions found no significant differences in joint motion angle [13]. Wang et al. concluded that the findings of their study supported the idea that the cervical joints accurately repeat their motion. Additionally, the direction of joint motion alternates between pro-directional joint motion (movement in the direction of neck motion) and anti-directional joint motion (movement in the opposite direction to that of neck motion) during neck motion [10]. The time periods and motion contributions in degrees of pro-directional and anti-directional joint motion vary, and are scattered through healthy cervical flexion and extension. Anti-directional joint motion is frequent during neck flexion and extension. For $\mathrm{C} 0-\mathrm{C} 7$ ROM anti-directional motion is approximately $40 \%$ of the pro-directional motion and approximately $70 \%$ of the resultant motion [10]. These results suggest that healthy cervical joints can move further than the motion found at end-range, and that this additional surplus motion is common during joint motion and may be necessary for normal healthy cervical joint motion.

Studies of cervical joint motion have previously demonstrated cervical joints with greater joint motion before end-range than at end-range [3,9]. Intuitively, a joint's ability to perform surplus motion would be necessary for simultaneous motion in multiple planes, as multiplane motion would be difficult if joint structures were fully stretched by motion in just one plane.

Assessment of maximal cervical joint motion in previous studies appears to be based on the assumption that cervical joints cannot move further than joint end-range and that joint motions are linear and continuous $[7,8]$. This assumption is not supported by more recent studies $[9-12,14,15]$. The aims of this study were firstly, to describe the maximum pro-directional and anti-directional joint motion in $10 \%$ epochs between the initial upright position and the end-range position, exploring the relationship between maximum joint motion and joint endrange. Secondly, to analyse the maximum surplus joint motion in quartiles, and to suggest possible subdivisions of joint motion and joint classification based on type of motion. This study proposes a joint classification of single cervical joint motion types based on end range (terminal position) and the maximum joint motion.

\section{Methods and materials Definitions of concepts}

Anti-directional surplus motion refers to surplus joint motion in opposition to the primary motion direction.

End-range refers in this study to the end or terminal position of a joint motion. 
Epoch: An epoch is defined as a time period representative of $10 \%$ of the total time required to complete a flexion or extension neck motion.

Maximum motion refers to the maximum joint motion in degrees measured during a video fluoroscopy motion excursion. Maximum motion can also refer to the maximum motion capacity of an individual joint.

Motion excursion: A motion task performed from point A-to point B. In the case of this study, from upright to end range cervical flexion or end-range cervical extension.

Motion type refers to a classification of a single joint's motion during neck motion. We have defined 3 types of motion, and all are defined according to their end-range.

1) Classic $(\mathrm{C})$, where the maximum motion = terminal position.

2) Surplus (S), this type is classified using prodirectional surplus motion, where maximum motion is more than the terminal position.

3) Anti-directional (A) where the terminal position is less than the start position. In this study, the start position is upright and the terminal position is endrange.

Pro-directional surplus motion refers to surplus motion found beyond end-range.

Range of motion (ROM) refers to the angular motion in degrees between the start position of the motion and the end position of the motion (end-range) - range of motion can be of an individual joint or of the neck and can be measured from static or video images.

Surplus motion refers to joint motion that occurs outside the boundaries of upright (start position) and endrange. Surplus motion is the difference, in degrees, between the upright start position or the end-range position and the maximum motion for a single joint. Surplus motion can be pro-directional or antidirectional and a single joint can produce surplus motion in both directions.

Upright refers in this study to the upright start position of neck motions.

\section{Subjects}

Due to the increased risk of cancer posed to healthy subjects by exposure to ionizing radiation, data was extracted and re-analysed from a previous study investigating the repeatability of cervical joint motion [13]. Subjects were aged between 20 and 37 and were recruited from campus and via social media, and in accordance with the following exclusion criteria: possible pregnancy, inflammatory or neurological disorders, cervical trauma, or neck pain in the last 3 months. Subjects were paid US \$22 an hour.
All participants signed informed consent forms prior to participating in the study. The study was conducted in accordance with the Helsinki declaration and ethical approval was given by the regional ethics committee (N20140004).

\section{Experimental procedures}

Both the reproducibility of image analysis and the experimental procedures have been previously published [16]. Prior to the fluoroscopic procedure subjects were instructed to practice the flexion and extension motion excursions. The subjects were instructed to follow with their eyes a line marked on the floor, wall and ceiling in order to reduce out of plane motion. Custom glasses were worn, the attached external markers provided better visual tracking of the occiput. One complete excursion was to be performed with a smooth and even tempo and to be completed at $16 \mathrm{~s}$, with $2 \mathrm{~s}$ at the upright and $2 \mathrm{~s}$ at end-range positions. Subjects practiced the timed motion before imaging began and the researcher counted out loud while the subject performed the excursion under video fluoroscopy. The motion excursions were performed while sitting with knees, hips, ankles and elbows at $90^{\circ}[10,17]$.

\section{Motion analysis}

Two motion directions were analysed (flexion and extension) for 7 cervical joints in 33 subjects. The motion was analysed in $10 \%$ time epochs of total cervical motion. Total joint motion and total neck ROM were obtained by calculating the sum of the motion across the $10 \%$ epochs. Maximum motion, surplus motion and endrange were extracted for each joint.

Joints were subdivided into three types according to their end-range motion: Type $C$, end-range motion equals maximum motion; type $\mathrm{S}$, end-range motion is less than maximum motion and type $\mathrm{A}$, joints with antidirectional end-range motion.

Figure 1 illustrates the three types of motion and Fig. 2 demonstrates representative cases of these motions.

\section{Fluoroscopic recordings}

The source-to-subject difference was $76 \mathrm{~cm}$, and was measured prior to exposure. The fluoroscope produces $45 \mathrm{KV}, 208 \mathrm{~mA}, 6.0 \mathrm{~ms}$ X-ray pulses at 25 frames per second (Philips BV Libra, 2006, Netherland). The estimated average radiation exposure from the two fluoroscopic videos was $0.24 \mathrm{mSv}$ (PCXMC software, STUK, Helsinki, Finland).

\section{Image analysis}

Manual image analysis was performed using a MATL AB-based program [16]. Twenty-two osseous points were marked in accordance with previously validated 


\section{Joint motion types}

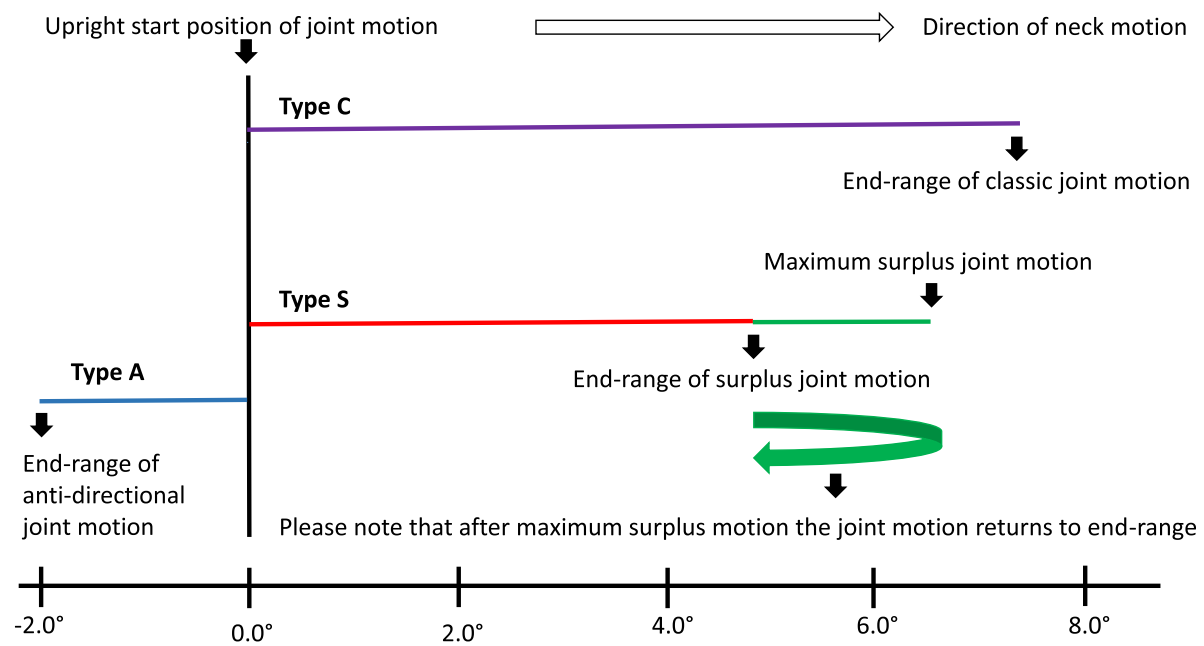

Fig. 1 Joint motion types. Three types of cervical joint motion 1) C 2) S and 3) A. The joint motion type C illustrates the common perception of joint motion from upright along the purple line to end-range. Type $\mathrm{C}$ joint motion has no pro-directional surplus motion. This type of motion is documented in almost half of all cervical joints. Type $\mathrm{S}$ joint motion is illustrated by the red line, and beyond end-range by the green line. Almost half of the joint motion in this study was type $\mathrm{S}$. The green returning arrow illustrates that the motion passes the point of end-range, before the end of neck motion, and continues to the point of maximum surplus joint motion. It then moves anti-directionally towards the endrange position. Type A joint motion terminates in the opposite direction to that of head motion. This type of joint motion is demonstrated by approximately $6 \%$ of all cervical joints and is illustrated by the blue line

and published procedures $[8,10,16,17]$. "The marking points were 2 anterior and 2 posterior external markers for occiput (C), 2 points at the centers of the medullary cavities of anterior and posterior arcs of atlas (C1), 2 inferior corners of axis (C2), 2 superior corners of the seventh vertebra (C7), and the anterior and posterior corners of the superior and inferior endplates of the third to the sixth vertebrae (C3-C6)" [13].
The MATLAB program calculated joint rotation in degrees using the vertebral midplane with respect to the horizontal plane, calculating the joint midline position from two neighboring mid-planes $[8,10,11,16,17]$. Positive degrees indicate joint motion in extension and negative degrees indicate joint motion in flexion; either motion direction could be anti-directional with respect to the pro-directional neck motion.

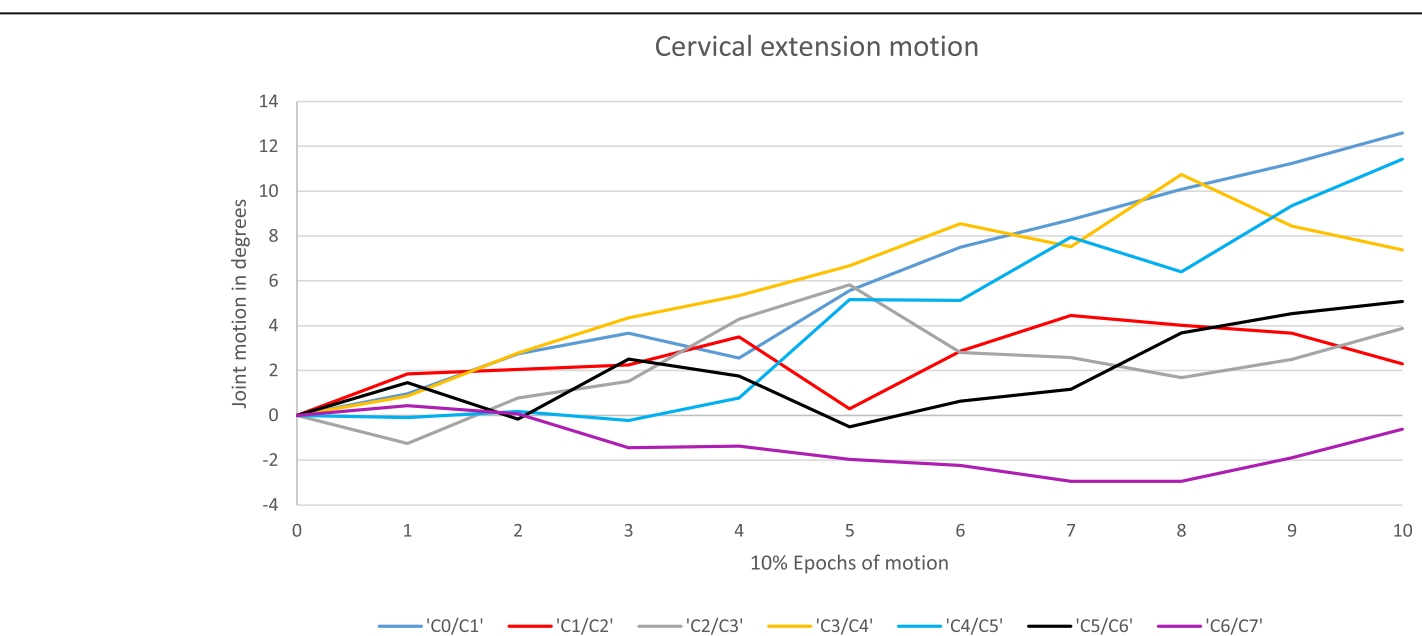

Fig. 2 Cervical extension motion for an individual subject. $C 0 / C 1, C 4 / C 5$ and $C 5 / C 6$ are type $C$ joints, producing maximum motion at end-range. $\mathrm{C} 1 / \mathrm{C}_{2}, \mathrm{C} 2 / \mathrm{C} 3$ and $\mathrm{C} 3 / \mathrm{C} 4$ is are type $\mathrm{S}$ joints, reaching maximum motion in the 7 th, 5 th and 8 th epochs respectively. C6/C7 is a type $\mathrm{A}$ joint, terminating its motion anti-directionally 


\section{Statistical analysis}

Two-hundred and thirty-one joints were included in the data set, each joint performed one flexion motion and one extension motion. The initial analysis was of all joints. The secondary stage excluded joints with antidirectional end-range (12 joints for flexion and 14 for extension) in order to focus on pro-directional surplus joint motion, as the primary aim of this study was to provide a quantitative assessment of the difference between maximum joint motion and joint end-range in healthy subjects. Tertiary stage analysis assessed surplus joint motion in quartiles of the associated end-range joint motions, with the smallest end-ranges in the first quartile and the largest in the fourth. This stage involved the analysis of 113 Type S joints for flexion and 109 Type $\mathrm{S}$ joints for extension. The surplus joint motion (marked with green in Fig. 1) was expressed in degrees and percentages of joint end-range motion (marked with red in Fig. 1). The motion and percentages of prodirectional surplus motion were first averaged across quartiles and then averaged across joints. The quartile data was further divided into upper cervical joints $(\mathrm{C} 0$ and C3) and lower cervical joints (C3 and C7). The cervical spine was divided in this way due to earlier findings from the research group. Wang et al. reported that the two regions behave differently, perhaps as a result of the anatomical differences of these regions [10].

Mann-Whitney $U$ tests were performed in order to compare the pro-directional end-range joint motion of type $\mathrm{C}$ and type $\mathrm{S}$. Type $\mathrm{C}$ is illustrated in purple in Fig. 1. Statistical analysis was performed on eleven joints after the exclusion of joint sample sizes of less than seven. Three joints were excluded due to a low sample size (for flexion $\mathrm{C} 1 / \mathrm{C} 2$ and $\mathrm{C} 6 / \mathrm{C} 7$ and for extension $\mathrm{C} 0 /$ C1). Minimum sample size for statistical tests was set at $n=7$.

The final stage re-introduced type A, 12 joints for flexion and 14 for extension, (marked with blue in Fig. 1) and looked at the frequency and contribution to motion for each of the three joint types.

Data was tested for Normality using Shapiro-Wilk and Kolmogorov-Smirnov test in SPSS (IBM Statistics 26). Comparisons of joint motion were performed with independent sample t-tests and Mann Whitney U tests. Significance was accepted at $p<0.05$. Data was presented as mean $\pm \mathrm{SD}$ and in percentages of end-range joint motion. The average, standard deviation and range were calculated for individual joints and across joints.

\section{Results}

Thirty-three subjects participated in the study, of which 12 were female. The demographics for the subjects can be found in Table 1 .
Table 1 Subject Demographics. Demographic characteristics of the 33 subjects included in this study. Age, height, weight and body mass index (BMI) are shown as a mean \pm SD

\begin{tabular}{lll}
\hline Demographics & Males (21) & Females (12) \\
\hline Age (years) & $27.0 \pm 5.3$ & $23.8 \pm 3.0$ \\
Height $(\mathrm{cm})$ & $179.0 \pm 8.4$ & $164.4 \pm 7.9$ \\
Weight $(\mathrm{kg})$ & $73.7 \pm 9.7$ & $61.2 \pm 12.6$ \\
$\mathrm{BMl}(\mathrm{kg} / \mathrm{m} 2)$ & $22.9 \pm 1.8$ & $22.5 \pm 2.9$ \\
\hline
\end{tabular}

Six joints $(\mathrm{C} 2 / \mathrm{C} 3, \mathrm{C} 3 / \mathrm{C} 4$ and $\mathrm{C} 4 / \mathrm{C} 5$ for flexion and $\mathrm{C} 1 / \mathrm{C} 2, \mathrm{C} 3 / \mathrm{C} 4$ and $\mathrm{C} 6 / \mathrm{C} 7$ for extension) out of the eleven joints $(\mathrm{C} 0 / \mathrm{C} 1, \mathrm{C} 2 / \mathrm{C} 3, \mathrm{C} 3 / \mathrm{C} 4, \mathrm{C} 4 / \mathrm{C} 5$ and $\mathrm{C} 5 / \mathrm{C} 6$ for flexion and $\mathrm{C} 1 / \mathrm{C} 2, \mathrm{C} 2 / \mathrm{C} 3, \mathrm{C} 3 / \mathrm{C} 4, \mathrm{C} 4 / \mathrm{C} 5, \mathrm{C} 5 / \mathrm{C} 6$, $\mathrm{C6} / \mathrm{C} 7$ for extension) showed significantly larger motion $(p<0.05)$ in degrees for type $\mathrm{C}$ compared to type $\mathrm{S}$ (Table 2). Joint motion in degrees, was for all eleven joints, numerically larger for type $\mathrm{C}$ than for type $\mathrm{S}$.

\section{Joint motion - flexion}

Of the 231 joints included in the study for flexion motion, 106 joints (45.9\%) were type C, 113 joints (48.9\%) were type S, and 12 (5.2\%) were type A.

The average pro-directional surplus joint motion was $2.41^{\circ} \pm 2.12^{\circ}$ and range $\left(0.07^{\circ}-14.23^{\circ}\right)$. Average surplus joint motion in the upper cervical (C0-C3) region, $3.07^{\circ}$ $\pm 2.46^{\circ}$ range $\left(0.07^{\circ}-.23^{\circ}\right)$, was greater than in the lower cervical region $(\mathrm{C} 3-\mathrm{C} 7), 1.60^{\circ} \pm 1.22^{\circ}$ range $\left(0.10^{\circ}-\right.$ $\left.5.01^{\circ}\right)$. The pro-directional surplus flexion motion is presented in Table 3.

\section{Quartiles of surplus flexion motion}

The pro-directional surplus flexion joint motion was divided into quartiles of the associated end-range joint motion, with the smallest end-ranges in the first quartile and the largest in the fourth. Flexion motion surplus to end-range was demonstrated by 113 joints.

The quartile with the smallest end-ranges had an average pro-directional surplus joint motion of $2.79^{\circ}$, which was $152.0 \%$ of the associated end-range joint motion. The quartile with the largest end-ranges had an average pro-directional surplus joint motion of $1.94^{\circ}$, which was $24.3 \%$ of the averaged associated end-range joint motion.

Percentages of average pro-directional surplus flexion joint motion ranged from 21.2 to $359.4 \%$ in the upper cervical quartiles and from 0.8 to $94.0 \%$ in the lower cervical quartiles. In flexion, the upper cervical quartiles ranged from $1.18^{\circ}$ to $4.36^{\circ}$ and from $0.12^{\circ}$ to $5.46^{\circ}$ in the lower cervical quartiles. Average surplus joint motion as a percentage of end-range joint motion decreased with an increase in end-range joint motion. However, there was no clear pattern of data distribution for surplus motion in degrees (Table 4). 
Table 2 Comparisons between type $C$ and type $\mathrm{S}$. The Mann-Whitney $U$ comparisons of pro-directional end-range motion between type $\mathrm{C}$ and type $\mathrm{S}$. Motion direction and joints for comparison are shown in rows one and two, rows three and four show the joint motion as a mean \pm SD of type $C$ and type $S$. ${ }^{a}$ No data available, insufficient sample size of one group

\begin{tabular}{|c|c|c|c|c|c|c|c|}
\hline \multicolumn{8}{|l|}{ Flexion } \\
\hline Joints & $\mathrm{CO} / \mathrm{C} 1$ & $\mathrm{C} 1 / \mathrm{C} 2^{\mathrm{a}}$ & $\mathrm{C} 2 / \mathrm{C} 3$ & $\mathrm{C} 3 / \mathrm{C} 4$ & $\mathrm{C} 4 / \mathrm{C} 5$ & $\mathrm{C} 5 / \mathrm{C} 6$ & $\mathrm{C} 6 / \mathrm{C7}^{\mathrm{a}}$ \\
\hline Type C & $-4.2^{\circ}\left(4.0^{\circ}\right)$ & & $-5.1^{\circ}\left(1.7^{\circ}\right)$ & $-9.5^{\circ}\left(2.4^{\circ}\right)$ & $-11.0^{\circ}\left(4.0^{\circ}\right)$ & $-11.9^{\circ}\left(3.9^{\circ}\right)$ & \\
\hline Type S & $-2.8^{\circ}\left(2.1^{\circ}\right)$ & & $-4.9^{\circ}\left(3.6^{\circ}\right)$ & $-5.4^{\circ}\left(3.0^{\circ}\right)$ & $-6.7^{\circ}\left(4.1^{\circ}\right)$ & $-9.3^{\circ}\left(4.6^{\circ}\right)$ & \\
\hline$P$ & 0.759 & & 0.000 & 0.001 & 0.005 & 0.127 & \\
\hline \multicolumn{8}{|l|}{ Extension } \\
\hline Joints & $\mathrm{C} 0 / \mathrm{C}^{\mathrm{a}}$ & $\mathrm{C} 1 / \mathrm{C} 2$ & $\mathrm{C} 2 / \mathrm{C} 3$ & $\mathrm{C} 3 / \mathrm{C} 4$ & $\mathrm{C} 4 / \mathrm{C} 5$ & $\mathrm{C} 5 / \mathrm{C} 6$ & $\mathrm{C} 6 / \mathrm{C} 7$ \\
\hline Type C & & $10.6^{\circ}\left(3.2^{\circ}\right)$ & $6.2^{\circ}\left(3.2^{\circ}\right)$ & $10.1^{\circ}\left(3.9^{\circ}\right)$ & $11.1^{\circ}\left(4.1^{\circ}\right)$ & $8.6^{\circ}\left(3.9^{\circ}\right)$ & $7.8^{\circ}\left(4.8^{\circ}\right)$ \\
\hline Type S & & $6.4^{\circ}\left(4.3^{\circ}\right)$ & $5.4^{\circ}\left(3.5^{\circ}\right)$ & $6.08^{\circ}\left(3.7^{\circ}\right)$ & $9.3^{\circ}\left(4.6^{\circ}\right)$ & $8.4^{\circ}\left(5.0^{\circ}\right)$ & $3.5^{\circ}\left(2.0^{\circ}\right)$ \\
\hline $\mathbf{P}$ & & 0.004 & 0.507 & 0.013 & 0.224 & 0.709 & 0.013 \\
\hline
\end{tabular}

\section{Joint motion- extension}

Of the 231 joints included in the study for extension motion, 108 joints (46.8\%) were type C, 109 joints (47.2\%) were type $\mathrm{S}$ and 14 joints (6.1\%) were type A. The average pro-directional surplus joint motion was $2.02^{\circ} \pm 1.70^{\circ}$ range $\left(0.04^{\circ}-6.97^{\circ}\right)$.

As with flexion the average pro-directional surplus joint motion in the upper cervical region $2.84^{\circ} \pm 1.91^{\circ}$ range $\left(0.05^{\circ}-6.97^{\circ}\right)$ was numerically larger than in the lower cervical region $1.42^{\circ} \pm 1.27^{\circ}$ range $\left(0.04-4.75^{\circ}\right)$. The pro-directional surplus extension motion is presented in Table 3.

\section{Quartiles of surplus extension motion}

The pro-directional surplus extension joint motion was divided into quartiles of the associated endrange joint motion, smallest end-ranges in the first quartile, largest in the fourth. The quartile with the smallest end-ranges demonstrated an average prodirectional surplus joint motion of $2.21^{\circ}$, which was $87.5 \%$ of the associated end-range joint motion. The quartile with the largest end-ranges demonstrated an average pro-directional surplus joint motion of $1.43^{\circ}$, which was $10.3 \%$ of the associated end-range joint motion. The quartile percentage range across the upper cervical joints was 8.6 to $232.3 \%$ and across the lower cervical joints was 2.2 to $137.5 \%$ (Table 4). Surplus extension motion for the upper cervical joints ranged between $0.96^{\circ}$ and $4.53^{\circ}$, the range for the lower cervical joints was between $0.33^{\circ}$ and $3.20^{\circ}$. Average surplus joint motion, both in degrees, and as a percentage of end range joint motion decreased as end-ranges increased.

\section{Anti-directional end-range motion}

Anti-directional end-range motion was demonstrated by $5.2 \%$ of cervical joints during flexion motion and $6.1 \%$ of cervical joints during extension motion. Of those joints, $0.9 \%$ during flexion and $2.2 \%$ during extension moved anti-directionally from the outset and never passed upright pro-directionally.

For flexion, the average anti-directional motion was $2.33^{\circ} \pm 2.53^{\circ}$ with a range of $0.03^{\circ}$ to $18.50^{\circ}$. For extension, the average anti-directional motion was $2.24^{\circ}$ $\pm 1.71^{\circ}$ with a range of $0.09^{\circ}$ to $8.73^{\circ}$. Anti-directional end-range motion was found predominantly in the upper cervical region. Eleven of the 12 joints exhibiting anti-directional end-range in flexion, and 9 of the 14 in extension were found at the $\mathrm{C} 0 / \mathrm{C} 1-\mathrm{C} 2 / \mathrm{C} 3$ levels (Table 5).

On average 1 out of every 18 joints produced antidirectional end-range.

Table 3 Pro-directional surplus joint motion. Pro-directional surplus motion, SD and range in degrees for flexion and extension joint motion (C0/C1 to C6/C7). No significant differences were found between flexion and extension surplus motion

\begin{tabular}{|c|c|c|c|c|c|c|c|}
\hline & $\mathrm{CO} / \mathrm{C} 1$ & $\mathrm{C} 1 / \mathrm{C} 2$ & $\mathrm{C} 2 / \mathrm{C} 3$ & $\mathrm{C} 3 / \mathrm{C} 4$ & $\mathrm{C} 4 / \mathrm{C} 5$ & $\mathrm{C} 5 / \mathrm{C} 6$ & $\mathrm{C6} / \mathrm{C7}$ \\
\hline Average Flexion & $2.36^{\circ}$ & $3.92^{\circ}$ & $2.71^{\circ}$ & $1.82^{\circ}$ & $1.47^{\circ}$ & $1.40^{\circ}$ & $1.48^{\circ}$ \\
\hline SD Flexion & $3.20^{\circ}$ & $2.37^{\circ}$ & $1.65^{\circ}$ & $1.03^{\circ}$ & $1.18^{\circ}$ & $1.35^{\circ}$ & $2.00^{\circ}$ \\
\hline Flexion Range & $0.07^{\circ}-14.23^{\circ}$ & $0.26^{\circ}-7.33^{\circ}$ & $0.07^{\circ}-5.41^{\circ}$ & $0.19^{\circ}-3.62^{\circ}$ & $0.18^{\circ}-4.27^{\circ}$ & $0.10^{\circ}-4.33^{\circ}$ & $0.38^{\circ}-5.01^{\circ}$ \\
\hline Average Extension & $1.99^{\circ}$ & $3.38^{\circ}$ & $2.57^{\circ}$ & $1.45^{\circ}$ & $1.08^{\circ}$ & $1.78^{\circ}$ & $1.34^{\circ}$ \\
\hline SD Extension & $1.42^{\circ}$ & $1.95^{\circ}$ & $1.97^{\circ}$ & $1.18^{\circ}$ & $1.15^{\circ}$ & $1.70^{\circ}$ & $0.96^{\circ}$ \\
\hline Extension Range & $0.02^{\circ}-4.5^{\circ}$ & $0.05^{\circ}-6.97^{\circ}$ & $0.57^{\circ}-6.77^{\circ}$ & $0.20^{\circ}-5.75^{\circ}$ & $0.06^{\circ}-4.57^{\circ}$ & $0.04^{\circ}-4.56^{\circ}$ & $0.08^{\circ}-3.42^{\circ}$ \\
\hline
\end{tabular}


Table 4 Joint motion surplus to end-range in quartiles. The quartiles of pro-directional surplus flexion and extension motion for joints $\mathrm{CO} / \mathrm{C} 1$ to $\mathrm{C6} / \mathrm{C} 7$. The motions were divided into quartiles of end-range motion, with the smallest end-range motion in quartile 1 and the largest end-range motion in quartile 4. Each quartile shows the pro-directional surplus motion in degrees and as a percentage of the associated end-range motion. The first column from the left shows quartiles, the second column shows motion direction, degrees and percentages and the next seven columns show joints C0/C1, C1/C2, C2/C3, C3/C4, C4/C5, C5/C6 and C6/C7, the last two columns show upper cervical joints $\mathrm{CO} / \mathrm{C} 3$ and lower cervical joints $\mathrm{C} 3 / \mathrm{C} 7$. The table is divided in two, with the upper half showing flexion motion and a lower half showing extension motion. The number of joints in each quartile is given in the bottom row of each half. The calculations for flexion of C5/C6 and C6/C7 included only 8 and 5 joints respectively. The smallest number of joint observations in the extension table was eight, seen at C0/C1

\begin{tabular}{|c|c|c|c|c|c|c|c|c|c|c|}
\hline Quartile & Flexion & $\mathrm{COC1}$ & $\mathrm{C} 1 \mathrm{C} 2$ & $\mathrm{C} 2 \mathrm{C} 3$ & $\mathrm{C} 3 \mathrm{C} 4$ & C4C5 & $\mathrm{C5C6}$ & $\mathrm{C6C7}$ & $\mathrm{COC} 3$ & $\mathrm{C} 3 \mathrm{C7}$ \\
\hline 1 & Degrees & $2.20^{\circ}$ & $4.36^{\circ}$ & $4.13^{\circ}$ & $1.96^{\circ}$ & $2.50^{\circ}$ & $1.68^{\circ}$ & $2.73^{\circ}$ & $3.56^{\circ}$ & $2.22^{\circ}$ \\
\hline 1 & Percent & $200.70 \%$ & $204.06 \%$ & $359.44 \%$ & $92.64 \%$ & $93.97 \%$ & $37.43 \%$ & $75.65 \%$ & $254.73 \%$ & $74.92 \%$ \\
\hline 2 & Degrees & $1.52^{\circ}$ & $2.92^{\circ}$ & $3.76^{\circ}$ & $2.26^{\circ}$ & $0.57^{\circ}$ & $2.56^{\circ}$ & $0.44^{\circ}$ & $2.73^{\circ}$ & $1.45^{\circ}$ \\
\hline 2 & Percent & $78.63 \%$ & $62.41 \%$ & $100.75 \%$ & $50.42 \%$ & $11.93 \%$ & $38.11 \%$ & $7.87 \%$ & $80.60 \%$ & $27.08 \%$ \\
\hline 3 & Degrees & $1.91^{\circ}$ & $4.35^{\circ}$ & $1.18^{\circ}$ & $1.44^{\circ}$ & $1.49^{\circ}$ & $1.25^{\circ}$ & $0.38^{\circ}$ & $2.48^{\circ}$ & $1.14^{\circ}$ \\
\hline 3 & Percent & $69.01 \%$ & $61.71 \%$ & $21.16 \%$ & $25.61 \%$ & $20.38 \%$ & $11.61 \%$ & $4.04 \%$ & $50.62 \%$ & $15.41 \%$ \\
\hline 4 & Degrees & $3.86^{\circ}$ & $3.33^{\circ}$ & $2.41^{\circ}$ & $1.63^{\circ}$ & $1.14^{\circ}$ & $0.12^{\circ}$ & $1.12^{\circ}$ & $3.20^{\circ}$ & $1.0^{\circ}$ \\
\hline 4 & Percent & $76.01 \%$ & $31.31 \%$ & $26.26 \%$ & $17.10 \%$ & $9.59 \%$ & $0.77 \%$ & $8.85 \%$ & $44.52 \%$ & $9.08 \%$ \\
\hline \multicolumn{2}{|c|}{ Number of joints } & 18 & 22 & 22 & 20 & 18 & 8 & 5 & 62 & 51 \\
\hline Quartile & Extension & $\mathrm{COC} 1$ & $\mathrm{C} 1 \mathrm{C} 2$ & $\mathrm{C} 2 \mathrm{C} 3$ & $\mathrm{C} 3 \mathrm{C} 4$ & $\mathrm{C} 4 \mathrm{C} 5$ & $\mathrm{C} 5 \mathrm{C} 6$ & $\mathrm{C} 6 \mathrm{C7}$ & $\mathrm{COC} 3$ & $\mathrm{C} 3 \mathrm{C7}$ \\
\hline 1 & Degrees & $2.38^{\circ}$ & $4.53^{\circ}$ & $3.37^{\circ}$ & $1.51^{\circ}$ & $1.25^{\circ}$ & $0.99^{\circ}$ & $1.49^{\circ}$ & $3.43^{\circ}$ & $1.31^{\circ}$ \\
\hline 1 & Percent & $184.00 \%$ & $171.05 \%$ & $232.31 \%$ & $89.68 \%$ & $33.89 \%$ & $29.69 \%$ & $137.52 \%$ & $195.85 \%$ & $72.69 \%$ \\
\hline 2 & Degrees & $1.92^{\circ}$ & $3.26^{\circ}$ & $1.73^{\circ}$ & $2.02^{\circ}$ & $1.73^{\circ}$ & $3.20^{\circ}$ & $1.20^{\circ}$ & $2.30^{\circ}$ & $2.04^{\circ}$ \\
\hline 2 & Percent & $35.05 \%$ & $75.04 \%$ & $48.18 \%$ & $40.39 \%$ & $25.11 \%$ & $53.14 \%$ & $36.12 \%$ & $52.75 \%$ & $38.69 \%$ \\
\hline 3 & Degrees & $0.96^{\circ}$ & $2.64^{\circ}$ & $2.88^{\circ}$ & $1.61^{\circ}$ & $0.77^{\circ}$ & $2.39^{\circ}$ & $1.22^{\circ}$ & $2.16^{\circ}$ & $1.45^{\circ}$ \\
\hline 3 & Percent & $8.55 \%$ & $40.16 \%$ & $46.93 \%$ & $22.44 \%$ & $7.31 \%$ & $28.85 \%$ & $27.24 \%$ & $31.88 \%$ & $21.46 \%$ \\
\hline 4 & Degrees & $2.68^{\circ}$ & $3.11^{\circ}$ & $1.28^{\circ}$ & $0.66^{\circ}$ & $0.33^{\circ}$ & $0.52^{\circ}$ & $1.42^{\circ}$ & $2.36^{\circ}$ & $0.74^{\circ}$ \\
\hline 4 & Percent & $12.39 \%$ & $25.81 \%$ & $13.19 \%$ & $6.35 \%$ & $2.24 \%$ & $3.27 \%$ & 24.42 & $17.13 \%$ & $9.07 \%$ \\
\hline \multicolumn{2}{|c|}{ Number of joints } & 8 & 20 & 16 & 16 & 16 & 16 & 17 & 44 & 65 \\
\hline
\end{tabular}

\section{Frequency of surplus motion}

The end-range position was passed pro-directionally in flexion by $54.1 \%$ and in extension by $52.3 \%$ of the 231 joints. Similarly, the upright position was passed antidirectionally by $52.3 \%$ of joints in flexion and $53.3 \%$ of all 231 joints in extension. Both the upright position and the end-range position were passed by $22.9 \%$ of all 231 joints during flexion and extension.

\section{Average joint motion}

The average contribution to cervical ROM (C0 to C7) was in fact larger for type $C$ than for type $S$, with

Table 5 Anti-directional joint motion. Table 5 shows anti-directional end-range motion and anti-directional surplus motion for flexion and extension

\begin{tabular}{|c|c|c|c|c|c|c|c|c|}
\hline \multirow[b]{3}{*}{ Joints } & \multicolumn{4}{|c|}{ Anti-directional flexion } & \multicolumn{4}{|c|}{ Anti-directional extension } \\
\hline & \multicolumn{2}{|c|}{ End-range } & \multicolumn{2}{|c|}{ Surplus } & \multicolumn{2}{|c|}{ End-range } & \multicolumn{2}{|c|}{ Surplus } \\
\hline & Count & Mean \pm SD & Count & Mean \pm SD & Count & Mean \pm SD & Count & Mean \pm SD \\
\hline $\mathrm{CO} / \mathrm{C} 1$ & 5 & $2.93 \pm(1.53)$ & 13 & $2.18 \pm(1.93)$ & 1 & 2.72 & 12 & $2.15 \pm(1.42)$ \\
\hline $\mathrm{C} 1 / \mathrm{C} 2$ & 5 & $5.97 \pm(2.68)$ & 14 & $3.11 \pm(4.67)$ & 4 & $3.72 \pm(0.98)$ & 8 & $2.47 \pm(1.73)$ \\
\hline $\mathrm{C} 2 / \mathrm{C} 3$ & 1 & 2.16 & 14 & $2.08 \pm(1.71)$ & 4 & $1.84 \pm(1.48)$ & 15 & $2.83 \pm(1.82)$ \\
\hline $\mathrm{C} 3 / \mathrm{C} 4$ & - & - & 13 & $1.26 \pm(0.92)$ & 1 & 0.3 & 14 & $1.78 \pm(1.30)$ \\
\hline $\mathrm{C} 4 / \mathrm{C} 5$ & - & - & 9 & $1.20 \pm(1.07)$ & - & - & 10 & $1.65 \pm(1.23)$ \\
\hline $\mathrm{C} 5 / \mathrm{C} 6$ & - & - & 16 & $1.27 \pm(1.03)$ & - & - & 15 & $1.23 \pm(0.87)$ \\
\hline $\mathrm{C} 6 / \mathrm{C} 7$ & 1 & 0.32 & 18 & $2.04 \pm 1.75)$ & 4 & - & 21 & $1.80 \pm(1.38)$ \\
\hline
\end{tabular}


contributions $60.23^{\circ}$ and $67.86^{\circ}$ for type $C$ and $42.22^{\circ}$ and $49.05^{\circ}$ for type $\mathrm{S}$, for flexion and extension respectively.

The average joint motion from upright to end-range for all 33 subjects before and after exclusion of type A joints is presented in Fig. 3. No type A joints were found at the $\mathrm{C} 4 / \mathrm{C} 5$ and $\mathrm{C} 5 / \mathrm{C} 6$ level. However, type A motion excursions were found at the remaining cervical joint levels. The figure illustrates the difference between endrange and maximum motion of type $\mathrm{S}$ across joints. The maximum demonstrated joint motion across subjects for each joint measured in this study is presented in Table 6.

Assessment of average flexion and extension joint motion of all joints using t-tests showed a significant difference $(P<0.0001)$ for $\mathrm{C} 0 / \mathrm{C} 1$, where $11.85^{\circ}$ of extension was considerably larger than $-2.33^{\circ}$ of flexion. In contrast flexion, at $-11.26^{\circ}$ for $\mathrm{C} 5 / \mathrm{C} 6$ and $-10.01^{\circ}$ for $\mathrm{C} 6 /$ $\mathrm{C} 7$ was significantly larger than extension, at $8.51^{\circ}$ for
Table 6 Maximum demonstrated motion. The maximum demonstrated flexion and extension motion in degrees

\begin{tabular}{llllllll}
\hline & C0C1 & C1C2 & C2C3 & C3C4 & C4C5 & C5C6 & C6C7 \\
\hline Flexion & 17.7 & 19.4 & 15.6 & 12.8 & 20.4 & 18.6 & 18.3 \\
Extension & 26.7 & 21.2 & 14.6 & 18.0 & 17.8 & 19.4 & 16.3 \\
\hline
\end{tabular}

$\mathrm{C} 5 / \mathrm{C} 6$ and $4.56^{\circ}$, for $\mathrm{C6} / \mathrm{C} 7,(P<0.05)$ and $(P<0.0001)$ respectively.

The end-range joint motions of type $\mathrm{C}$ and type $\mathrm{S}$ were significantly different for $\mathrm{C} 2 / \mathrm{C} 3, \mathrm{C} 3 / \mathrm{C} 4$ and $\mathrm{C} 4 / \mathrm{C} 5$ $(P<0.01)$ in flexion and $\mathrm{C} 1 / \mathrm{C} 2, \mathrm{C} 3 / \mathrm{C} 4$ and $\mathrm{C} 6 / \mathrm{C} 7(P<$ 0.05 ) in extension (Table 2).

\section{Discussion}

This study changes our understanding of cervical motion by demonstrating that a little under half of the cervical joints (48.1\%) produced pro-directional surplus motion with an average of approximately $2^{\circ}$. Surplus motion
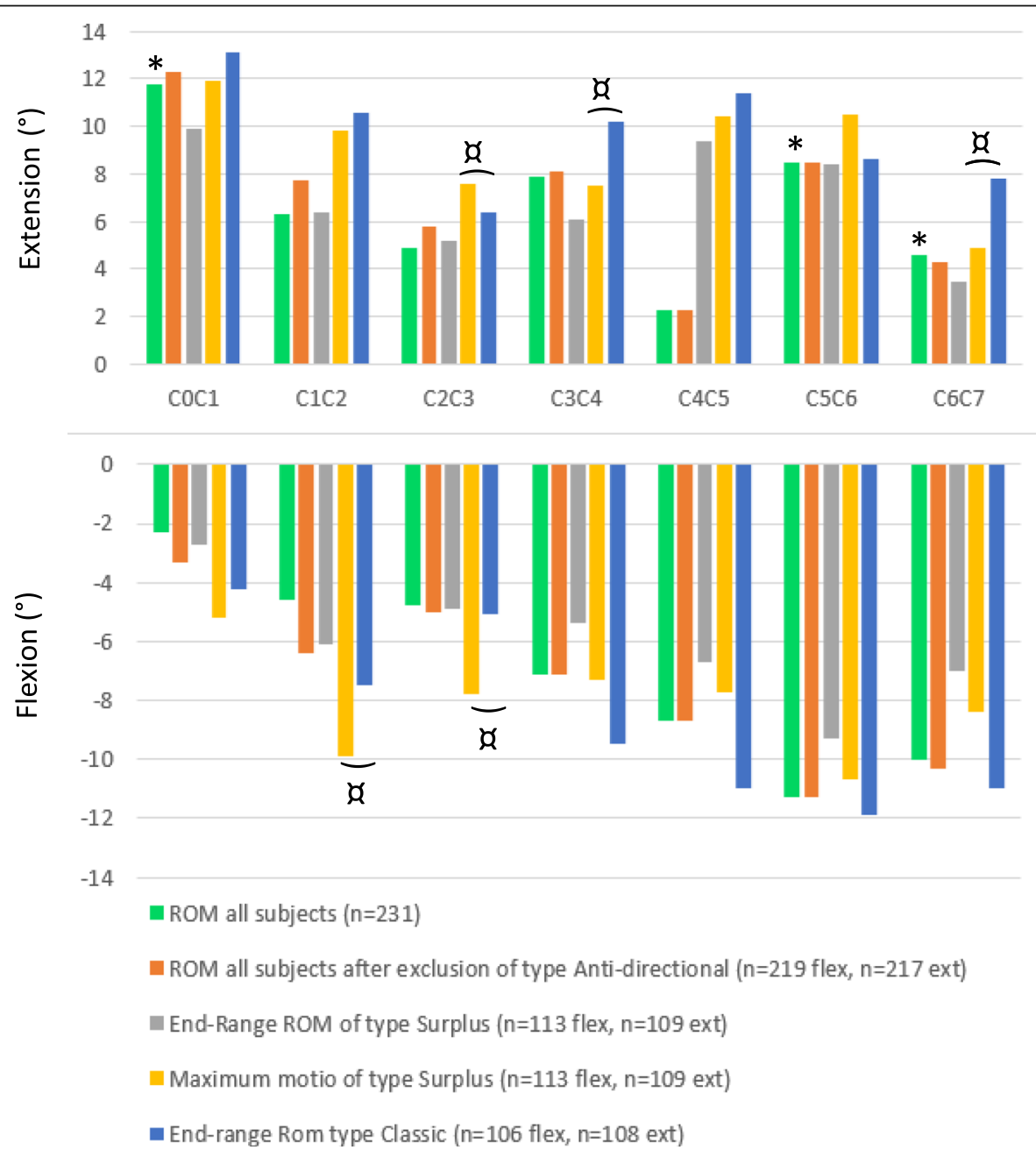

Fig. 3 Average flexion and extension joint ROM. * Indicates a significant difference when comparing average flexion and extension. $x$ indicates a significant difference in the end-range motion of type $S$ and type $C$ 
should not be considered abnormal as 113 out of 219 joints in flexion and 109 out of 217 joints for extension demonstrated joint motion surplus to end-range.

Approximately $1 / 5$ of all joints demonstrated both pro-directional and anti-directional surplus motion, passing upright and end-range positions with similar frequency. Those joints that did not produce prodirectional surplus joint motion (type C) comprised $46.3 \%$ of the total joints.

Interestingly $5.7 \%$ of all joints displayed antidirectional end-range joint motion (type A).

Type A joints were found predominantly in the upper cervical region, with only a few in the mid and lower cervical regions, suggesting that the anatomical structure of the vertebrae may influence the prevalence of this motion $[9,18]$. The finding that joints can complete their motion in opposition to the direction of head motion is not unexpected. Previous documentation that large proportions of anti-directional cervical flexion and extension motions were normal in healthy subjects, gave some indication of this possibility $[10,13]$.

\section{Surplus motion}

This study suggests that it may be possible to use the average pro-directional surplus joint motion as a percentage of end-range ROM as an indicator for the reliability of end-range motion to predict the maximum joint motion. Analysis of the quartiles of surplus motion demonstrated a clear pattern for both flexion and extension. Surplus joint motion as a percentage of end-range joint motion decreased with an increase in end-range motion.

As small end-ranges are associated with large percentages of surplus motion, using end-range in these situations to predict a joint's maximum motion should be done with caution. Conversely, it could be argued that large end-ranges can be more readily utilised as a predictor for maximum joint motion due to their association with small percentages of surplus motion. This does however question the reliability of flexionextension X-rays as an accurate indicator for a joints maximum motion.

\section{Maximum demonstrated joint motion}

The data suggests that the end-range motion does not reflect the maximum possible motion for an individual joint. This is especially clear for $\mathrm{C} 0 / \mathrm{C} 1$ during flexion, where the average ROM was $2.33^{\circ}$ and the average prodirectional surplus motion was $2.36^{\circ}$ with a range up to $14.23^{\circ}$. The upper cervical joint appeared to flex in the beginning of the flexion motion excursion, but to move anti-directionally later in the motion, towards a lesser degree of flexion. The small average motion of $\mathrm{C} / \mathrm{C} 1$ does not reflect the maximum motion capacity of $\mathrm{C} 0 / \mathrm{C} 1$ during flexion. This is illustrated by the maximum joint motion of type $\mathrm{S}$ for $\mathrm{C} 0 / \mathrm{C} 1$ (Fig. 3) and the large range for pro-directional surplus motion for $\mathrm{C} 0 / \mathrm{C} 1$, shown in Table 3. The maximum possible motion of healthy cervical joints is therefore unknown. It is not clear if the maximum measured motion found for all single joints in this study reflects the maximum possible motion capacity of healthy cervical joints, but we consider this unlikely.

The average cervical ROM measured between upright and end-range in this study was similar to previous reports despite differences in the methodology $[3,8,9]$.

Cervical joint motion between upright and end-range positions has previously been assessed by Wu et al. using video fluoroscopy. In this case motion was assessed in ranges of one third and the $\mathrm{C} 0 / \mathrm{C} 1$ joint was omitted from the study. The current study showed that endrange flexion and end-range extension joint motion were significantly different for $\mathrm{C} 0 / \mathrm{C} 1, \mathrm{C} 5 / \mathrm{C} 6$ and $\mathrm{C} 6 / \mathrm{C} 7$. By assessing $\mathrm{ROM}$ in $10 \%$ epochs, this study aimed to give a more detailed picture of the joint motion pattern. The $\mathrm{C} 0 / \mathrm{C} 1$ joint was also included in this study as we know it to be important in its contribution to cervical spine motion [15].

The cervical flexion motion of $\mathrm{C} 0 / \mathrm{C} 1\left(2.3^{\circ}\right)$ demonstrated the smallest average joint motion found in this study. No previous studies have reported the amount of motion found between upright and end-range flexion for $\mathrm{C} 0 / \mathrm{C} 1$. One study reported end-range flexion to endrange extension motion for $\mathrm{C} 0 / \mathrm{C} 1$, and the combined flexion and extension motion of that study was comparable to the findings of this study [8].

\section{Clinical implications}

The results indicate that the end-range motion seen on flexion-extension $\mathrm{X}$-rays may not be reliable for the diagnosis of reduced joint motion, as joints with small end-range motion were associated with large surplus joint motion percentages. In contrast, cervical joints with large end-range motion were associated with small percentages of surplus joint motion, consequently offering a more reliable prediction of the maximum motion of a joint. It is a reasonable consideration that in order for the joints of the cervical spine to produce multiplane motion, a joint's motion capacity cannot be expended by motion in a single plane. However, it is clear that in most clinical interpretations of neck motion the concept of surplus motion is not applied.

Orthopedic surgeons use the terminology compensation for additional joint motion found in joints adjacent to a surgical fusion. Several biomechanical studies have documented a mechanism by which adjacent unfused levels compensate for the loss of cervical range of motion (ROM) in fused levels [19]. The compensation is 
perceived as a new ability for further cervical single joint motion; however, the compensation may be pre-existing surplus motion of the adjacent joints. This clinical implication may raise the question: is the success of surgical fusion dependent upon pre-surgical surplus motion in the adjacent joints?

Chiropractors have previously used the term paraphysiological space to explain the motion which allows an adjustment to occur when a cervical joint is brought to tension.

However, it is possible that the para-physiological space may simply be the surplus motion of the cervical joints. It would seem that we cannot fully understand cervical motion during a physical examination, the fixation or the manipulation without first having a better understanding of surplus joint motion. The complexity of joint motion has been demonstrated in recent research [10, 13, 17, 20-22].

\section{Study limitations}

Quantification and analysis of video-fluoroscopy has some limitations. The largest confounder is the measurement error; however, the experimental procedures and reproducibility of image analysis have previously been published [16]. High reliability of the vertebral marking procedure has been established and high ICCs have been documented in previous studies $[10,16]$.

Likewise, repeatability of the joint motion angle has previously been published [13]. Although Wang et al. [13] demonstrated that cervical joints accurately repeat their motion; it must be acknowledged that they were not investigating surplus motion, but joint motion angles.

It may be considered a limitation of the study that data was taken from a single motion excursion, rather than taking an average of multiple excursions, however this decision was made in order to reduce radiation exposure to subjects.

The study group was primarily younger adult males and females, which raises the question: are the results applicable to an older population? Other demographic or anatomical stratification for sex, age, height, weight, posture, and type of neck: long, thin, short and amount of adipose tissue, may also influence the cervical ROM and the study results, potentially limiting their application.

Variations in the curvature of the neck, were not considered central to the investigation as all patients were deemed healthy and screened for previous trauma, disease processes or episodes of previous cervical pain. Additionally, cervical ROM in this study was similar to the results of previous studies $[3,8,9]$.

It is recognised in this study that surplus joint motion can be both pro-directional and anti-directional and that some joints produce surplus motions in both directions. For the purpose of clarity, and because the focus of this paper is maximum pro-directional joint motion, joint classification in this study is based on end-range. While type $\mathrm{C}$ joints in this study do not demonstrate prodirectional surplus motion, a proportion of these joints is very likely to produce anti-direction surplus motion. Likewise, a proportion of type $\mathrm{S}$ joints will likely produce anti-directional surplus motion. It is also of note that the variability in joint motion will influence how joints are grouped (type $\mathrm{C}, \mathrm{S}$ and $\mathrm{A}$ ) from motion to motion.

It could also be argued that the study is limited by the choice only to include flexion and extension, as this does not allow us to investigate the full dynamic capability of the joints in multiple planes. However, there must be consideration given to the level of radiation exposure healthy subjects are subjected to.

\section{Future studies}

Future studies may look at the effect of variations in the cervical lordosis and age, among other demographic variations, on the prevalence and distribution of surplus joint motion in healthy adults.

The quantification of surplus motion will provide reference values against which symptomatic patient data can be compared. Future investigations into the effect of pain on surplus motion would be beneficial, in order to establish the diagnostic utility of surplus joint motion. Studies of pain effects on joint motion have documented that both experimental and recurrent neck pain altered anti-directional motion patterns in the cervical spine [20-22]. Lastly a more detailed classification of joint types may be of interest, addressing the prevalence of anti-directional surplus motion.

\section{Conclusion}

This is the first study to categorise joints by type of motion. Type $\mathrm{S}$ constituted approximately half of the joints analysed in this study. Therefore, end-range motion cannot be assumed to be a demonstration of a joint's maximum motion. This brings into question the reliability of flexion/extension X-rays as a measure of the total motion capacity of the cervical spine. The traditional view of joint motion seems to describe the motion pattern of a type $C$ joint. Only half the joints represented in this study produced a type $\mathrm{C}$ motion pattern, suggesting that the traditional view of joint motion represents an incomplete picture.

Until now the presence of surplus joint motion has been acknowledged, but never quantified, yet it is undeniably a persistent finding.

\section{Acknowledgements}

Niels Peter Bak Carstens is acknowledged for providing the fluoroscopy facilities at Vejgaard Kiropraktisk Klinik, Aalborg, Denmark. 


\section{Authors' contributions}

Conception and design: VBA, XW, RL. Acquisition and data: XW. Analysis and interpretation of data: $V B A, X W, M D Z, L R \varnothing, M P$, RL. Drafting of the manuscript: VBA, XW, RL. Critical revision of the manuscript for important intellectual content: MDZ, LRØ, MP, RL. Statistical analysis: VBA, XW, LRØ, MP. Obtaining funding: VBA, XW, RL. Supervision: XW, MDZ, LRØ, RL. No additional contributions: RL. All authors read and approved the final manuscript.

\section{Funding}

This study has been funded through the PhD funding awarded to Victoria Elizabeth Blogg Andersen by Kiropraktor Fonden Denmark.

\section{Availability of data and materials}

The datasets generated and/or analysed during the current study are not publicly available due to data protection of participants but are available from the corresponding author on reasonable request.

\section{Declarations}

Ethics approval and consent to participate

All participants signed informed consent forms prior to participating in the study. The study was conducted in accordance with the Helsinki declaration and ethical approval was given by the Scientific Ethical Committee for the region of Northern Jutland (N20140004).

\section{Consent for publication}

All participants gave consent to publication and signed the appropriate forms prior to participating in the study.

\section{Competing interests}

The authors declare that they have no competing interests.

\section{Author details}

'Department of Health Science and Technology, Aalborg University, 9220 Aalborg, Denmark. ${ }^{2}$ The Second Hospital of Jilin University, Jilin University, Qianjin St. 2699, Changchun 130021, China. ${ }^{3}$ Sport Sciences - Performance and Technology, Department of Health Science and Technology, Aalborg University, 9220 Aalborg, Denmark.

Received: 14 October 2020 Accepted: 4 May 2021

Published online: 25 May 2021

\section{References}

1. Hino H. Dynamic motion analysis of normal and unstable cervical spines using cineradiography: an in vivo study. Spine. 1999;24(2):163

2. Houck J, Yack HJ, Mulhausen P. Neck mobility: the influence of age and a history of neck pain. Gait Posture. 1997;2(5):184.

3. Wu S, Kuo L, Lan HH, Tsai S, Su F. Segmental percentage contributions of cervical spine during different motion ranges of flexion and extension. Clin Spine Surg. 2010;23(4):278-84.

4. Tousignant M, Duclos E, Lafleche S, Mayer A, Tousignant-Laflamme Y, Brosseau $L$, et al. Validity study for the cervical range of motion device used for lateral flexion in patients with neck pain. Spine. 2002;27(8):812-7. https:// doi.org/10.1097/00007632-200204150-00007

5. Tousignant M, Smeesters C, Breton A, Breton É, Corriveau H. Criterion validity study of the cervical range of motion (CROM) device for rotational range of motion on healthy adults. J Orthop Sports Phys Ther. 2006;36(4): 242-8. https://doi.org/10.2519/jospt.2006.36.4.242.

6. Hsieh C, Yeung BW. Active neck motion measurements with a tape measure. J Orthop Sports Phys Ther. 1986;8(2):88-92. https://doi.org/10.25 9/jospt.1986.8.2.88.

7. Wu S, Kuo L, Lan HH, Tsai S, Chen C, Su F. The quantitative measurements of the intervertebral angulation and translation during cervical flexion and extension. Eur Spine J. 2007;16(9):1435-44. https://doi.org/10.1007/s00586007-0372-4

8. Frobin W, Leivseth G, Biggemann M, Brinckmann P. Sagittal plane segmental motion of the cervical spine. A new precision measurement protocol and normal motion data of healthy adults. Clin Biomech. 2002; 17(1):21-31. https://doi.org/10.1016/S0268-0033(01)00105-X.
9. Bogduk N, Mercer S. Biomechanics of the cervical spine. I: Normal kinematics. Clin Biomech. 2000;15(9):633-48. https://doi.org/10.1016/S02680033(00)00034-6.

10. Wang $X$, Lindstroem R, Plocharski M, Østergaaard LR, Graven-Nielsen T. Cervical flexion and extension includes anti-directional cervical joint motion in healthy adults. Spine J. 2018;18(1):147-54. https://doi.org/10.1016/j. spinee.2017.07.170.

11. Branney J, Breen AC. Does inter-vertebral range of motion increase after spinal manipulation? A prospective cohort study. Chiropr Man Therap. 2014 22(1):24.

12. Reinartz $R$, Platel $B$, Boselie $T$, van Mameren $H$, van Santbrink $H$, ter Haar Romeny B. Cervical vertebrae tracking in video-fluoroscopy using the normalized gradient field; 2009. p. 524-31.

13. Wang X, Lindstroem R, Plocharski M, Østergaard LR, Graven-Nielsen T. Repeatability of cervical joint flexion and extension within and between days. J Manip Physiol Ther. 2018;41(1):10-8. https://doi.org/10.1016/j.jmpt.2 017.08.005.

14. Anderst WJ, Donaldson WF, Lee JY, Kang JD. Cervical spine intervertebral kinematics with respect to the head are different during flexion and extension motions. J Biomech. 2013;46(8):1471-5. https://doi.org/10.1016/j. jbiomech.2013.03.004.

15. Anderst WJ, Donaldson WF, Lee JY, Kang JD. Cervical motion segment contributions to head motion during flexionlextension, lateral bending, and axial rotation. Spine J. 2015;15(12):2538-43. https://doi.org/10.1016/j.spinee.2 015.08.042.

16. Plocharski M, Lindstroem $R$, Lindstroem CF, Østergaard LR. Motion analysis of the cervical spine during extension and flexion: reliability of the vertebral marking procedure. Med Eng Phys. 2018;61:81-6. https://doi.org/10.1016/j. medengphy.2018.07.010.

17. Wang X, Lindstroem R, Carstens NPB, Graven-Nielsen T. Cervical spine reposition errors after cervical flexion and extension. BMC Musculoskelet Disord. 2017;18(1):102

18. Swartz EE, Floyd RT, Cendoma M. Cervical spine functional anatomy and the biomechanics of injury due to compressive loading. J Athl Train. 2005;40(3): 155.

19. Shin JJ. Comparison of adjacent segment degeneration, cervical alignment, and clinical outcomes after one-and multilevel anterior cervical discectomy and fusion. Neurospine. 2019;16(3):589.

20. Qu N, Lindstrøm R, Hirata RP, Graven-Nielsen T. Origin of neck pain and direction of movement influence dynamic cervical joint motion and pressure pain sensitivity. Clin Biomech. 2019;61:120-8. https://doi.org/10.101 6/j.clinbiomech.2018.12.002.

21. Qu N, Lindstrøm R, Graven-Nielsen T, Hirata RP. Experimental cervical interspinous ligament pain altered cervical joint motion during dynamic extension movement. Clin Biomech. 2019;65:65-72. https://doi.org/10.1016/j. clinbiomech.2019.04.002

22. Qu N, Graven-Nielsen T, Lindstrøm R, Dc VBA, Hirata RP. Recurrent neck pain patients exhibit altered joint motion pattern during cervical flexion and extension movements. Clin Biomech. 2020;71:125-32. https://doi.org/10.101 6/j.clinbiomech.2019.10.026.

\section{Publisher's Note}

Springer Nature remains neutral with regard to jurisdictional claims in published maps and institutional affiliations.

Ready to submit your research? Choose BMC and benefit from:

- fast, convenient online submission

- thorough peer review by experienced researchers in your field

- rapid publication on acceptance

- support for research data, including large and complex data types

- gold Open Access which fosters wider collaboration and increased citations

- maximum visibility for your research: over $100 \mathrm{M}$ website views per year

At BMC, research is always in progress.

Learn more biomedcentral.com/submission 